\title{
'Placing' Pedagogy and Curriculum Within an Ecological Worldview
}

\author{
JODI MACQUARRIE AND GILLIAN DIANE SMITH \\ Simon Fraser University, Canada
}

\begin{abstract}
Surveying the last two centuries, one might easily deduce the purpose of education has been to induct, or rather indoctrinate, students into a culture's dominant ontology and epistemology. In modern Western culture's prevailing education systems, this usually means atomistic, dualistic, and competitive ways of being and disembodied, decontextualized and dispassionate ways of knowing that focus on passively acquiring abstracted and fragmented knowledge. Given our current predicament of human alienation and ecological crisis, we suggest a new worldview is needed to reconceptualize human ways of living and being in, indeed valuing, our place within the ecosphere. In contrast to the modernist, mechanistic world view, which deems the natural world detached, valueless, and available for buman exploitation, an ecological worldview advocates a buman sense of self as interconnected and unified with the natural world. Moved by the work of philosophers, eco-theorists and eco-educators, this paper explores the role of the more-than-buman world in pedagogical and curricular processes and practices that align more closely with an ecological worldview. Our proposed praxis of ecological education was introduced and put into action with a group of educators at the Education With/Out Borders (EWOB) symposium at Sasamat, British Columbia, in October, 2008. An overview of the exercise and highlights from the group's concluding discussion of the experience are also presented.
\end{abstract}

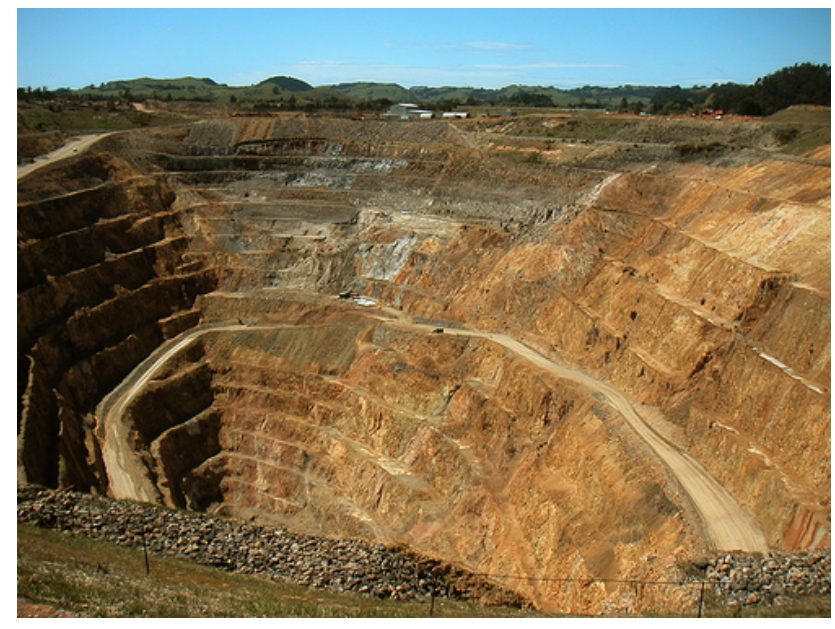

Please click on the image above or on the following link: Koyaanisqatsi movie clip (Coppola \& Reggio, 1982)

(C) Copyright 2009. The authors, Jodi MacQuarrie and Gillian Diane Smith, assign to the SFU Educational Review the right of first publication and educational and non-profit institutions a non-exclusive license to use this document for personal use and in courses of instruction provided that the article is used in full and this copyright statement is reproduced. Any other usage is probibited without the express permission of the author. The licensor of the image is Jon Wiley who has licensed it under the Creative Commons Attribute-Noncommercial 2.0 Generic license. You are free to use the image as specified in the license. Accessed on April 2, 2009. 


\section{The Hopi Prophecies}

If we dig precious things from the land, we will invite disaster.

Near the Day of Purification, there will be cobwebs spun back and forth in the sky. A container of ashes might one day be thrown from the sky, which could burn the land and boil the oceans.

\section{KO.YAA.NIS.QATSI: N. 1. Crazy Life 2. Life in Turmoil 3. Life Disintegrating 4. Life out of Balance 5. A State of Life that Calls for Another Way of Living}

Images of a world in disarray are what the Hopi people call koyaanisqatsi. If Hopi prophecies and perceptive commentators on today's world are to be believed, we are rapidly spiraling towards a level of environmental, social and personal chaos and destruction never before encountered. Rising greenhouse gas emissions and global warming are the largest issues threatening the planet, closely followed by the contamination of oceans and soils, the rapid depletion and extinction of living plant and animal species, and unimaginable poverty and starvation around the world. Life on Earth as we know it is in deep distress (Merchant, 2005; Orr, 2004; Naess, 1989; Devall \& Sessions, 1985). We suggest ecological deterioration, a casualty of diminution of relationships of non-dominance and disintegration of the innate value of all in the ecosphere ${ }^{1}$, is at the heart of this environmental degradation, political turmoil, and insensate violence committed in the name of belligerently exploitive economic policies. For four decades now, many educational theorists and eco-philosophers have joined these commentators and indigenous groups, such as the Hopi, in expressing deep sadness and concern for the plight of the ecosphere. They squarely implicate, among a plethora of systems, myths and pathologies, modern Western education. Orr (2004) suggests that what we face is a problem of education and not in education:

Much of what has gone wrong with the world is the result of education that alienates us from life in the name of human domination, fragments instead of unifies, overemphasizes success and careers, separates feeling from intellect and the practical from the theoretical, and unleashes on the world minds ignorant of their own ignorance. (p. 17)

From modern education we learn to first deny what we know in our very bones: that is, what is constituted in millions of years of ecological development. The prevailing educational paradigm ${ }^{2}$ teaches us to ignore our ecologically harmonious sense of self and world that arise out of what Shepard (1982) describes as an extraordinary and complicated interplay of separations and symbioses evolving from direct experiences with rich nonhuman environments, play at being animals, the study of natural history, small-group life with few possessions, ritual initiations, and mature adult mentorship. In fact, in

1 The term ecosphere, often used synonymously with biosphere, includes the sun, atmosphere, hydrosphere, lithosphere, sediments, and organisms in which all life occurs and interdependent processes alter and transform. Even a cursory examination of the historical roots of deterioration of the ecosphere reveals Western religions, sciences, technologies, and economies as the major culprits because they: promote exploitive and exclusionary (to women and Earth, for example) attitudes that see Man and Nature as dichotomous and Man as master; encourage habits of action dominated by an implicit faith in perpetual progress that is rooted in Judeo-Christian teleology; and foster uncritical acceptance of mechanistic, consumerist, and militaristic ways of being, knowing, and doing (Berry, 2008; Orr, 2004; Rowe, 1991; Shepard, 1982; White Jr., 1967).

2 The "modern education" and "prevailing educational paradigm" being discussed refer to dominant, largely North American, public and private Kindergarten through to post-secondary schools and institutions and their related curricula, practices, architecture, and larger systems and bodies of governance (e.g. School Boards, provincial Ministries of Education, University Senate Committees). 
his book Nature and Madness, he goes so far as to suggest we are a sick society, an infantile bunch of adults ontogenetically crippled by the will to destroy, a fear of separation, and fantasies of omnipotence. ${ }^{3}$ Arne Vetlesen (as cited in Bai, in press) proposes that our moral and empathic incompetencies are the consequence of psychic numbing;,most of us in the West appear to be wellschooled, tantrum-throwing automatons incapable of feeling and unable to perceive the pain and suffering inflicted upon others. Akin to Shepard's and others' claims of madness as an extensive failure in some fundamental dimension of human existence, Bai (in press) proposes the notion of ecological psychic numbing as a widespread cultural condition in modernity. Characterized by a kind of anesthetized disinterestedness, ecological psychic numbing is at the heart of insensate violence and environmental destructiveness. Vetlesen's and Bai's thoughts are echoed by eco-theologian Thomas Berry. Implicating not only the pervasive power of the technological trance and the myth of progress, Berry (as cited in Tucker, n.d. Section 3, para. 10) describes how our cultural pathology and deep alienation are due to a spiritual autism in relation to the natural world. Berry (1993) laments: "We no longer hear the voices of the rivers or the mountains, or the voices of the sea... Everything about us has become an "it" rather than a "thou" (para. 14). With our need to control and impose order, our stance in the world, Berry states, is to meet it as a "collection of objects rather than a communion of subjects" (para. 13).

What might we do, then, about the problem of education? How might we begin to address a cultural psychopathology that leads to such estrangement and destructive behaviours and start to heal the psychic numbing and ecological autism exacerbated by contemporary education? The problems seem insurmountable and the damage irreparable only if we succumb to responding in ways the dominant anthropocentric, individualistic, mechanistic paradigm calls forth and if we choose to merely tinker with existing (traditionally Western) systems and structures. ${ }^{4}$ It is fatuous to think that what lies ahead is going to be easy or that it has a simple fix; for what is required is nothing less than a change in the way we view the world. Almost two decades ago, Stan Rowe (1991) stressed that this change for education means:

A fresh purpose... to lead learners away from the ignorance of their species-centered universe to a wider more invigorating view of planet Earth as a creative being, inviting humanity's cooperation and care. Such a purpose, necessary to reorient humanity to the right order of things, challenges education at its deepest levels. It cannot be met simply by increasing the ecology content of the biological sciences or by ingeniously exploiting those occasional sympathetic references to Nature within the arts curriculum. The goal - new to us and strange requires a radical reversal of emphasis, shifting the spotlight away from humanity and focusing it on the world-in-which-humanity-exists-as-part (p. 8).

Accordingly, the purpose of this paper is to offer some theoretical groundwork on ecological worldview and suggest a framework for curriculum and pedagogy that extends from this worldview.

\footnotetext{
${ }^{3}$ Shepard is not alone in the assertion that contemporary Western society suffers from a psychopathology. In his book The Sane Society, Erich Fromm (1955) takes on a psychological analysis of our culture using a curious blending of neo-Freudian and Marxist theories to demonstrate, through the pathology of normalcy, how insane we are. Theodore Roszak (1993) argues that repression of the "living record of cosmic evolution", or what he calls the "ecologic unconscious", is the "deepest root of collusive madness in industrial society" (p. 48). Also representing the ecological voice, David Orr (2004) contends that the world reflects only "the demented image of the mind imprisoned within itself" and if our civilization were sane, we would have "more parks and fewer shopping malls; more small farms and fewer agribusinesses; more prosperous small towns and fewer cities; more solar collectors and fewer strip mines," and so on (p. 151).

${ }^{4}$ We acknowledge that this may not be true for all Western education systems and structures at all times. As was discussed previously, it is the dominant, or prevailing, educational paradigms to which we refer, and not alternate educational approaches, such as Waldorf Schools, A. S. Neill's Summerhill Schools, and Evergreen State College, to name a few.
} 
Since we are still in the early stages of reaching agreement on just what an ecological worldview is, this paper will begin with an admittedly short summary of select literature from philosophers, eco-theorists, and bioregionalists to identify some of the themes that form the bedrock of this view. Following that, we will describe and reflect on our experiences attempting to put this framework into practice with a group of educators at the Education With/Out Borders (EWOB) symposium.

\section{Tilling Fertile Ground: Unearthing Ecological Worldview}

Worldviews, or what are sometimes referred to as social paradigms, are comprehensive ways people understand and direct their lives. Also referred to as Weltanschaunng, they are concepts both answering deep philosophical questions about ontology, axiology, praxeology, epistemology and cosmology and through which we construct images of the world and come to understand our experiences in it (Naugle, 2002). Dominant worldviews are "collections of values, beliefs, habits, and norms which form the frame of reference for a collectivity of people" (Devall \& Sessions, 1985, p. 42). As such, like a pair of lenses through which we view the world, they become a logical system and set of evaluative assumptions and beliefs that determine what exists and what is identified as relevant. They form what we take to be a problem, how it will be solved, and what falls outside the realm of perception, thought, and responsibility. Tacitly communicated through "origin myths, cultural narratives, linguistic metaphors and cautionary tales" (Clark, 2002, p. 5), dominant worldviews permeate and (re)construct human consciousness to such an extent that we scarcely question their validity.

During the seventeenth century, a scientific view of the world emerged as just such a dominant paradigm. There was, and remains every sense that the universe is a machine, a closed system, analogous to a clock that could be manipulated by people and technology (Merchant, 2005; Skolimowski, 2005). Earth was seen as an infinite collection of dead matter, of resources, over which people have dominion. To these resources we have no obligations, and our use of them is limited only by their usefulness. Hence, it was in this mechanistic world view that the natural world was objectified, characterized and experienced as lifeless, static and unresponsive to human activity (Merchant, 2005; Skolimowski, 2005; Rorty, 1998; Abram, 1997). Scientists and philosophers of the era, such as Francis Bacon and René Descartes, advocated domination and control of this nature available for human benefit and consumption, thereby promoting a "nature placed in bondage through technology [that] would serve human beings" (Merchant, 2005, p. 45).

Despite its shortcomings, this philosophical position about the reality of nature is often the guiding principle for contemporary problem-solving and decision-making in government, science, technology, economics and education (Skolimowski, 2005). Notwithstanding the destructive and oppressive consequences of this tainted thinking and acting, the mechanistic world view prevalent in our schools today is rarely questioned; rather, it is accepted as part of an everyday reality (Merchant, 2005; Orr, 2004). From disconnected curricula and daily classroom activities that present mathematics, social sciences and language arts as separate subjects corresponding to school periods, to objective standardization of preferred knowledge and outcomes, we see example after example of how contemporary schooling reflects a fragmented, mechanistic philosophy. It is unsurprising that out of this philosophical stance there arises, analogous to the discrete subjects in school, the foundation of a self as distinct, bounded, and separate from itself as well as human and more-than-human others. The result of this is the slow, insidious growth of an intellectual and emotional detachment precursory to both psychic numbing and a view of knowledge as abstract and divorced from students' lived experiences.

We assert that an alternate perspective and ontology of self is required, namely one that puts self into the interconnected web of the natural world in which we-exist-as-part. Norwegian eco-philosopher Arne Naess offers such an understanding by providing an ecological framework for the conception of self. Concerned about the detachment resulting from, and utilitarianism promoted by the fragmented 
and narrow conception of self as realized in the dominant Western world view, Naess instead introduces the ecological self as the basis of self-realization and as integral to an ecological approach to being in the world. Reluctant to reify the concept of ecological self by defining it, Naess (1987) offers a single sentence: "the ecological self of a person is that with which this person identifies" (p. 35). Naess further argues that situations in which identification elicits intense empathy and increases compatibility would be ones in keeping with the development of an ecological self. He describes an occasion when he watched the unfortunate death of a flea under a microscope. He felt an intense empathy and compassion which, he suggests, would not have been so if he was not able to identify with the flea, to "see himself in the flea"; that if he were "alienated from the flea, not seeing intuitively anything resembling myself, the death struggle would have left me indifferent" (p. 36). This is the heart of what Naess (1989) described as deep ecology: deep identification of individuals (self) with all life forms (Self), or the development of self-in-Self.

It is important to clarify here that Naess does not speak of humans projecting subjective emotions, such as empathy, onto non-human others. Rather, the ecological self perceives and experiences other humans and more-than-humans as subjectivities in all their unique potentialities and actualities. Further, the intense empathy and compassion he describes resonates more with Buberian meeting and inclusion, an extension of the self, rather than the transposition of a self into another being or the projecting of feelings onto another for the purposes of objectification or instrumentalization (Buber, 1996). Also of note is Naess's elaboration on this development of self-inSelf. Unlike the anthropocentrism, dualism, and competitiveness so characteristic of modern Western culture's prevailing ontology, Naess laid out a bio-centric, or eco-centric, view. Within eco-centrism, all organisms and entities in the ecosphere, as parts of and in an interrelated whole, have an equal right to live and flourish, to reach their own individual forms, or potentialities, of unfolding and self-realization within the larger Self-realization. ${ }^{5}$ Continuing, Naess states that Self-realization "includes personal and community self-realization, but is conceived also to refer to an unfolding of reality as a totality" 6 (p. 84). Part of self-realization is realizing inherent potentialities and it extends to the other-than-human world, too. Plants, animals, mountains and rivers are all involved in processes of actualizing and not only do they have ways of realizing their own inherent potentialities, they can aid humans in the process as well ${ }^{7}$ when we interact directly with them, for it is in these interactions that we learn about diversity by directly experiencing the "creative expressiveness" and "expansion of life space" of these

\footnotetext{
${ }^{5}$ In Norwegian, the term is Selv-realisering, or "Self-realizing", which more accurately suggests an active condition and not a place or state one can reach, because complete Self-realization would require realization of all. The concept, while premised upon certain psychological, social and ontological hypotheses, reflects a process and is meant as a guideline for a way of living (Naess, 1989).

"Murray Bookchin (1991) reminds us how terms such as "whole", "community" and "totality" have "perilous nuances for a generation that has known fascism and other totalitarian ideologies" (p. 23). In these contexts, images of homogenization, standardization, repression and finality are evoked. In ecological contexts, however, these terms denote "dynamic unity of diversity": stability "achieved by ever-changing differentiation, by everexpanding diversity" (p. 24). Thus, when Naess speaks of "whole", "community" and the "unfolding of reality as a totality", he refers not to simple, immutable homogeneity but complexity and diversity characteristic of a unity, or stability, achieved through regulatory heterogeneity. Bookchin's critique also extends to the notion of "equal value", "rights to self-fulfillment" and "intrinsic worth" upon which Naess and other deep ecologists found ecological ethics. He claims that animals do not "know' much beyond what is imparted to them by their instincts and rudimentary survival skills that they acquire" (p. xxxiv) in everyday experience and that any "value", "rights" or "worth" animals, plants, rocks and streams have has been conferred upon them by humans. While an interesting response, we find the anthropocentric assumptions underlying his critique to be problematic and contradictory.
}

${ }^{7}$ In some cases, it has been suggested that humans can assist nature to increase diversity and complexity as well. See, for example, Michael Pollan's (2002) The Botany of Desire: A Plant's-eye View of the World, in which Pollan convincingly argues that "domesticated" species such as potatoes and tulips have co-evolved with humans to gratify certain human desires such that humans help them multiply and flourish in return. 
life forms (Naess, 1987, 1989; Devall \& Sessions, 1985). Therefore, by identifying and interacting not just with other humans but other life forms, we experience heightened self-realization through the increased diversity of ways of realizing the potentialities of life. This also implies that the opposite is possible: self-realization, the widening and deepening of the self, is hindered if the self-realization of others is hindered or if diversity decreases. However, ecological hindrances can be overcome, Naess (1987) insists, within an ecological worldview, in which all (life)forms would be free to unfold and develop to their fullest potential, to maximize diversity, unhindered by human domination but with tendencies which favor flourishing of the group or community at large. We do not preserve others in their being, but allow others to persevere in their being, to act out their own nature as a self rich in constitutive human-human and human-more-than-human relations.

Contrary to Naess's ecological conception of self, the prevailing educational paradigm privileges an individuated, autonomous self and endorses the uncritical reiteration of psychic numbing of this self. In turn, this supports mechanistic ontologies and epistemologies that render us deaf to nature. This destructive nuance of an external reality and objectified, abstracted knowledge and detached ways of knowing are perhaps best exemplified by Neil Evernden's description of severing the vocal chords of the world. Evernden (1993) developed this metaphor in reference to indoctrinated ecology students who become vivisectionists capable of killing living, sentient, feeling beings by virtue of an education that champions and values empirical knowledge and ways of knowing,. Committing such acts is facilitated by the routine precaution of experimental physiologists who sever animals' vocal cords before experiments so they are not affected by the animals' cries. Evernden extended the metaphor by suggesting that the knife is applied to not just the animals in experiments but to life itself. By "cutting the vocal cords" of life, he cautioned, we also destroy the "larynx of the biosphere" (p. 17) and remove ourselves from our relationship to the world so as to not hear its cries when we transform it into a mechanical, material object upon which we inflict imperious and exploitive harm.

Instead of severing the vocal $\mathrm{c}(\mathrm{h})$ ords of life, how might we listen to life? Conservationist and philosopher Aldo Leopold may have something to offer us here. In his book, A Sand County Almanac (SCA), Leopold presented an epistemology based on a shared, or communal, way of knowing and understanding necessary to practice the land ethic, a guide for responsibly limited and humbly aware human action toward and in an interdependent world. Using observations and lessons deeply rooted in place, Leopold (1966) describes how limits on behavior can be achieved by first re-conceiving and repositioning humans as members of a biotic community wherein humans' roles are changed from "conqueror of the land-community to plain member and citizen of it. It implies respect for his fellow members, and also respect for the community as such" (p. 240). This view suggests a different kind of relationship with the land; land that we might consider textual landscapes waiting to be read by the aware citizen. Leopold's land ethic also stresses that when humans read the "open and ever-present book of nature" (Callicott, 1989, p. 226), they do so with respect and humility and are guided by an ethical understanding of interconnectedness and limits. For example, Leopold (1996) helps us to appreciate the land by understanding the ways the text intersects with practical and ethical life. In reading the land, we are put in touch with a shared point of view with other life forms and entire ecosystems. He demonstrates how epistemic awareness could result from direct acquaintance with the rhythms of the land, leading us to become aware that we are indeed members of a living set of relationships. When he talks about the native plant, Silphium, for example, and how its destruction by herbicide or blade goes unnoticed because humans see little aesthetic value in these weeds, we come to understand how often we create a poverty of flora and, by extension, a paucity of knowledge about the natural world.

Listening to life and reading the land is also critical to Kirkpatrick Sale's vision of bioregionalism. Sale (1985) proposes bioregionalism as the philosophical instrument by which our species can overcome our ecological insanity and create an ecological worldview. Explaining that bioregionalism's vision is for us to "become dwellers in the land, to come to know the earth fully and honestly", Sale cogently asserted, "the crucial and perhaps only and all-encompassing task is [for us] to understand place, the immediate specific place where we live" (p. 42). By living closer to the land, one necessarily 
lives closer to the community, thereby promoting conditions and circumstances for local dwellers to enjoy the communitarian values of cooperation, participation, and reciprocity that enhance individual development and appreciation for interdependence.

Like Leopold and Sale, David Abram also believes that places have something to say and are the ground of direct human experience and embodied meaning-making. Interpreting Merleau-Ponty's work, Abram (as cited in Gruenewald, 2003) aimed to demonstrate how all sensible things, animate and inanimate, are alive and enter into a mutual interaction, an active interplay, with perceiving humans through direct experience. In his book The Spell of the Sensuous, Abram (1997) outlined a compelling phenomenological definition of the term participation as used by the anthropologist Lucien Levy-Bruhl to describe the nature of indigenous sensory perception:

Levy-Bruhl used the word "participation" to characterize the animalistic logic of indigenous, oral peoples - for whom ostensibly inanimate objects like stones or mountains are often thought to be alive, for whom certain names, spoken aloud, may be felt to influence at a distance the things or beings that they named, for whom particular plants, particular animals, particular persons and places and powers may all be felt to participate in one another's existence, influencing each other and being influenced in return. (p. 57)

This example of indigenous sensitivity to the local environment demonstrates that humans have the potential and innate awareness to participate in interconnected existence and interdependence within the natural world. It is via a renewed attentiveness to this perceptual dimension that Abram (1990) and others (Bookchin, 1991; Evernden, 1993) believe we can come to understand other modes of awareness that inhabit and even constitute this living world.

As Bruce Morito (2002) pointed out, there are no universal ecological principles that enjoy support from ecologists, and moreover, no key concepts that are free of ambiguity, disagreement over meaning, and inconsistency of use. Acknowledging that we might have indeed contributed to, and participated in, these very ambiguities and inconsistencies, a brief summary of the major contrasting ideas of mechanistic and ecological world views are presented as follows. To begin, conceptions of the self, and the ontology, epistemology, and axiology interconnected with this notion of self, have been reconceptualized from:

1) an aggregate or plurality of distinct individuals to a system of integrally related and intermingling parts which constitute a whole that is more than the sum of its parts;

2) dominators and conquerors of land to humble, compassionate beings-in-the-world who exercise discipline, restraint and attentive care in order to maintain an ecosystem's stability (dynamic equilibrium) and integrity;

3) objects seeking order, homogeneity and fulfillment of self-interests to complex and interrelated sets of processes seeking to maximize diversity and flourishing through the fulfillment of complementary roles (mutualism) and regulatory heterogeneity; and

4) autistic, psychically numb, to attuned, aware participants who hold, and act in accordance with, non-instrumental values for all in the ecosphere.

Admittedly, shifting from an anthropocentric to a bio- or eco- centric view has its challenges, and ones from which education cannot be excluded. Education, in its prevailing form, reinforces this instrumentalist fragmentation and the subsequent psychic and emotional disconnect. The next section of the paper investigates how we might avert all these by building upon an holistic, integrated approach to curriculum that aligns more closely with the ecological worldview described above. 


\section{Aligning Pedagogy and Curriculum With an Ecological Worldview: An Example From Education With/Out Borders}

Today, most curricula are not developed locally, nor does their implementation tend to focus students' attention on their own circumstances and ways of knowing. Learning then becomes something acquired and measured, predominantly through the use of externally-developed paper-and-pencil tasks and after passive memorization rather than an unmediated, full-bodied experience of the world.

What does all this mean for aligning pedagogical and curricular processes and practicing with an ecological worldview? First, it suggests one of the tools of curriculum is the diverse, natural outdoors. In a local and regionally specific nature, students interact with a greater diversity of beings. This, in turn, may lead to richer and more numerous opportunities for identification, thereby maximizing selfin-Self realization and an appreciation for diversity. ${ }^{8}$ These encounters, as explained above, can also help elucidate what students know and value, for it is ultimately through their actions, as care and sustainability over competition and exploitation, for example, that co-participants ${ }^{9}$ may gain insight into, and steer in a different direction if needed, a particular student's being-in-the-world. ${ }^{10}$ Further, the mediated experiences of school cannot replace direct physical experiences and the embodied, contextualized knowledge that results. Implications are that aspects of curriculum and pedagogy must be likewise embodied and contextualized. This may also mean repeated and frequent opportunities to physically demonstrate what is known and being learned. A concrete example might be students restoring a polluted section of local stream to its natural state.

In October 2008, an informal effort was made by the authors to engage educators in an ecocurricular exercise that took participants into the classroom outside in order to develop a flavor for ecological-based curriculum and pedagogy. We began our discussion in one of the cabins on-site with some casual discourse among participants about understandings of an ecological worldview, both personally and generally held among educators at large. Some of the themes that emerged during our discussion were those of concern for the natural world, the interconnectedness of nature and people, and worldviews that counter the destructive elements of consumerism and capitalism. One group member was vocal about her expectation, and subsequent disappointment, that we were not delivering a lecture or slide show to explain our conception of ecological worldview. We are pleased this resistance surfaced in our discussion, as we feel it represents the degree to which the mechanistic world view is entrenched in how we expect curriculum to be passively delivered. Moreover, resistance of this nature illustrates how challenging the transition to ecological worldview and its associated pedagogy is likely to be.

Nonetheless, through dialogue and continued support we were able to come to some understanding of an alternative approach more appropriately aligned with ecological worldview. In fact, this participant approached us long after the presentation and thanked us for our patience and for

\footnotetext{
${ }^{8}$ Researchers studying environmentalists who have strong ecological values and have chosen an environmental career attributed their commitment to "many hours spent outdoors in a keenly remembered wild or semi-wild place in childhood or adolescence, and an adult who taught respect for nature" (Chawla, as cited in Sobel, 2008). ${ }_{9}$ We use the term co-participants because, in keeping with an ecological worldview in which being, knowing, valuing and doing are relational processes, it would not be a single individual who is responsible for the curricular tasks and who would act as the final arbiter of values. Co-participants may include any of a group of students, teachers and other school and/or district staff, families, indigenous groups, as well as members of the local community, human and non-human alike, involved in educational projects in a particular place.

${ }_{10}$ We are quite sure the alarm bells are ringing! What ethical right do we have to intervene in a student's being-inthe-world? At a time when "we continue to educate the young for the most part as if there were no planetary emergency" (Orr, 2004, p. 2), we are inclined to rephrase the question to instead ask, "Why is it that we are so reluctant to take on the responsibility to do so?"
} 
continuing to involve her in the workshop, a pedagogy we felt was vital to the integrity of the presentation and its content.

After the discussion, the group was invited to participate in an activity held outside on the shores of Sasamat Lake. The first implication of ecological pedagogy and place-based curriculum we wanted to demonstrate to our group was to address ways to counter psychic numbing, or collective autism, so that we may begin to recognize and hear, as well as fully and truly act upon, what nature reflects back to us. One way to include this ecological voice was to include it in curricula. As a result, participants were presented with a fictitious yet possible scenario: Locals, such as schoolchildren and their families, indigenous elders, land developers, educators, and community groups, have all proposed a Kindergarten to Grade 7 school for the area. The proposal focused on development of a sustainable school of 150 students with consideration for the biodiversity of the region. The task was to take on the voice of a given role and participate in the planning and development of this eco-school. One set of voices not included in the proposal stage but significant for the development and evaluative processes was the eco-voice, or the voices of local forest and plants, water and air, animals, insects, spiders and soil. The larger group was broken down into smaller groups, each assuming one of the assigned roles.

Once the entire group came back together to discuss plans for building and servicing this sustainable school, it became clear how each group, at first, was advocating a particular position in keeping with their role as parents, the school board, or the eco-voices such as the trees and animals inhabiting the area. Over time, however, and as each participant group had to adjust after hearing, and considering the concerns of, the other groups, a clearer picture of the proposed school emerged: it would be accessible by transit so as to not pave over the landscape or have an excess of vehicular traffic; local waterways could be used to develop micro-hydroelectric stations, a project students would be involved in with respect to designing, building and maintaining such a structure; and buildings would be spread out along the shores of the lake so as to take advantage of the lay of the land and in order to not clear away a large tract of forest. To these suggestions were added local gardens, composting toilets, solar heating, collection of rainwater, changing the school calendar to be in session at times of year when less energy would be consumed, and focusing curriculum on the local place. Soon, we realized that one decision affected every other group in some ways, and that the effects were too numerous and complex to fully anticipate and address. In addition, participants pointed to and fully involved their immediate surroundings while engaging in the decision-making and problem-solving of the task at hand, suggesting how it is that we come to know in contextualized, social ways, and rely on trial and error, our own firsthand experiences, and the knowledge, wisdom and experience of others. The implications were immediately apparent: coming to know is as interdependent a process as any other ecological relationship. It means not just reading (text)books, listening to lectures or viewing videos but also embodied encounters with human and non-human others, intergenerational and cultural sharing, and talking with peers.

At the conclusion of the task, we briefly discussed assessment and evaluation of such a project and how that, too, might align with an ecological worldview. Aptly, the suggestion was that the focus be not on the individual, as is so characteristically the case in our system of grades, rankings and hierarchies of performance, but on the group. So significant is the group to bioregionalist Kirkpatrick Sale (1985) that he wrote, "If one were to look for the single basic building block of the ecological world, it would be the community" whereby community is defined by Sale as "an essentially selfsufficient and self-perpetuating collection of different species that have adapted as a whole to the conditions of their habitat" (p. 62). This community is a real place characterized by connectedness, interaction and interdependence. The good of the community as a whole, then, serves as a standard for the assessment and evaluation of its constitutive parts (Callicott, 1989). Participants and their work, therefore, would need to be evaluated based not only on competence - building a sustainable school but also on contribution to community well-being and sustainability. As such, our discussion ended with some suggestions about how assessment and evaluation could unfold within an ecological worldview. Participants could write letters to be submitted to a council of stakeholders outlining how 
their decisions and actions have contributed to the flourishing and diversity of the group, health of the school, and overall sustenance of the biotic community. Participants might also reflect on examples of when and how they fulfilled complementary roles that contributed to the group and community functioning in a reciprocal, non-hierarchical manner. Critics may claim that in such practices the individual's needs and interests would be subsumed by community ones and subordinated to those of the more dominant human others. However, it is only within individualist, competitive models that discipline, self-restraint, compliance and mutuality are deemed a sacrifice and overly altruistic. In ecological-based pedagogy, the notion of dominance is rejected in favour of equality among the participants and community members. Finally, and in response to such concerns, participants would also be responsible for evaluating one another and the degree to which they felt their voices were heard, respected and included in decision-making processes.

\section{LO.MA.QATSI: N. Life in Balance}

This project began with the Hopi word koyaanisqatsi, an unbalanced, crazy life calling for another way of living. In response to that call, and in seeking lomaqatsi, we have endeavored to unearth some of what it means to be, know, value and do within an ecological worldview and how and why we might align educational practices of curriculum and pedagogy with this worldview. This project is not the work of only one author. Rather, it is an analysis and synthesis of ideas experienced through reading and by talking with others and reflecting in place. It intends to enact a growing awareness that nature is profoundly pedagogical. It includes the voices of participants and nature in that response. And always and everywhere, we have been guided by the sagacious words of Aldo Leopold (1966): "A thing is right when it tends to preserve the integrity, stability and beauty of the biotic community. It is wrong when it tends otherwise" (p. 262).

\section{Acknowledgments}

\section{Celebrating the Cross-Pollination of Ideas...}

Abram, D. (1990). Animal thinking. The Trumpeter, 7(4). Retrieved June 18, 2008, from http://trumpeter.athabascau.ca/index.php/trumpet/article/view/476/796

Abram, D. (1997). The spell of the sensuous: Perception and language in a more than buman world. New York: Random House.

Bai, H. (in press). Re-animating the universe: Environmental education and philosophical animism. In M. McKenzie, H. Bai, P. Hart, \& B. Jickling (Eds.), Fields of green: Re-imagining education. New Jersey: Hampton Press.

Berry, T. (1993). The meadow across the creek. In T. Berry, The great work: Our way into the future. Retrieved July 2, 2008, from http://www.thomasberry.org/Essays/MeadowAcrossCreek.html

Berry, W. (2008). Faustian economics: Hell hath no limits. Harper's Magazine. May. Retrieved June 29, 2008, from http://harpers.org/archive/2008/05/0082022

Bookchin, M. (1991). The ecology of freedom: The emergence and dissolution of bierarchy. Montreal: Black Rose Books.

Buber, M. (1996). I and thou. (W. Kaufmann, Trans.). New York: Touchstone. (Original work published 1970.) 
Callicott, J. Baird. (1989). In defense of the land ethic: Essays in environmental philosophy. Albany, NY: State University of New York Press.

Clark, M. (2002). In search of human nature. London: Routledge.

Coppola, F. (Producer), \& Reggio, G. (Director). (1982). Koyaanisqatsi [Motion picture]. USA: Island Entertainment/Palm Pictures.

Devall, B., \& Sessions, G. (1985). Deep ecology: Living as if nature mattered. Layton, UT: Gibbs M. Smith.

Evernden, N. (1993). The natural alien: Humankind and environment ( $2^{\text {nd }}$ ed.). Toronto, ON: University of Toronto Press.

Fromm, E. (1955). The sane society. New York: Rinehart.

Gruenewald, D. (2003). A multidisciplinary framework for place-conscious education. American Educational research Journal, 40(3), 619-654.

Leopold, A. (1966). A sand county almanac. New York: Ballantine.

Merchant, C. (2005). Radical ecology: The search for a livable world. New York: Routledge.

Morito, B. (2002). Thinking ecologically: Environmental thought, values and policy. Halifax, NS: Fernwood.

Naess, A. (1987). Self-realization: An ecological approach to being in the world. The Trumpeter, 4(3), 3542.

Naess, A. (1989). Ecology, community and lifestyle: Outline of an ecosophy. (D. Rothenberg, Trans.). Cambridge, UK: Cambridge University Press.

Naugle, D. K. (2002). Worldview: The history of a concept. Cambridge, UK: Wm. B. Eerdmans Publishing.

Orr, D. (2004). Earth in mind: On education, environment, and the human prospect. Washington, DC: Island Press.

Rorty, A. (1998). The ruling history of education. In. A. Oksenberg Rorty (Ed.), Philosophers on education: New historical perspectives (pp. 1-13). London: Routledge.

Roszak, T. (1993). Awakening the ecological unconscious. In Context: A Quarterly of Humane Sustainable Culture, 34, 48-51. Retrieved June 12, 2008, from http://www.context.org/ICLIB/IC34/Roszak.htm

Rowe, S. (1991). Education for a new world view. The Trumpeter, 8(3).

Sale, K. (1985). Dwellers in the land: The bioregional vision. San Francisco, CA: Sierra Club Books.

Skolimowski, H. (2005). Philosophy for a new civilization. New Delhi: Gyan.

Shepard, P. (1982). Nature and madness. Athens, GA: University of Georgia Press.

Sobel, D. (2008). Childhood and nature: Design principles for educators. Portland, ME: Stenhouse Publishers.

Tucker, M. E. (n.d.). Thomas Berry and the new story [PDF document]. Retrieved from Lecture Notes Online Web Site: http://www.earth-community.org/images/TuckerEssay.pdf

White Jr., L. (1967). The historical roots of our ecologic crisis. Science, 155, 1203-1207.

\section{About the Authors}

Jodi MacQuarrie and Gillian Smith are PhD students in Curriculum Theory and Implementation (Philosophy) at SFU. They can be contacted at jodimacquarrie@shaw.ca and gds1@sfu.ca. 